\title{
3 Research Square

\section{Ultrasound-guided Nusinersen Administration for Spinal Muscular Atrophy Patients With Severe Scoliosis: a Retrospective Single-arm Cohort Study}

Jiao Zhang

Peking Union Medical College Hospital https://orcid.org/0000-0003-3874-6505

Xulei Cui ( $\nabla$ cuixulei10685@pumch.cn )

Peking Union Medical College Hospital https://orcid.org/0000-0001-9570-1587

Si Chen

Peking Union Medical College Hospital

Yi Dai

Peking Union Medical College Hospital

Yuguang Huang

Peking Union Medical College Hospital

Shuyang Zhang

Peking Union Medical College Hospital

Research

Keywords: Spinal muscular atrophy, Severe scoliosis, Ultrasound-guided, Lumbar puncture

Posted Date: February 15th, 2021

DOI: https://doi.org/10.21203/rs.3.rs-202232/v1

License: (c) (i) This work is licensed under a Creative Commons Attribution 4.0 International License.

Read Full License 


\section{Abstract}

\section{Background}

This observational study describes our experience delivering nusinersen through lumbar puncture with real-time ultrasound guidance in spinal muscular atrophy (SMA) patients with severe scoliosis.

\section{Results}

Intrathecal nusinersen via real-time ultrasound-guided lumbar puncture was given to 3 patients who had severe thoracic and lumbar scoliosis: a 34-year-old female with type 3 SMA, a 28-year-old male with type 2 SMA, and a 14-year-old girl with type 3 SMA. Lumbar puncture was performed without sedation under ultrasound guidance using a $22 \mathrm{G}$ echogenic needle in the interlaminar aspect of the L4-L5 or L5-S1 interspace and a full dose of nusinersen $(12 \mathrm{mg} / 5 \mathrm{~mL})$ was injected after visualizing free cerebrospinal fluid (CSF) flow. Patients completed their 4 loading doses and 1 maintenance dose of nusinersen. All 15 procedures were successful and well tolerated.

\section{Conclusions}

Real-time ultrasound-guided lumbar puncture is an effective and radiation-free technique to administer intrathecal nusinersen in SMA patients with severe scoliosis when done by practitioners with expertise in this procedure.

\section{Background}

Spinal muscular atrophy (SMA) is a genetic, autosomal recessive neuromuscular disease with an incidence between 1 in 6,000 and 1 in 10,000 live births [1]. Pathogenetically, SMA is caused by a homozygous deletion in the survival motor neuron 1 (SMN1) gene on chromosome $5 q 13$, which leads to insufficient levels of SMN protein [2,3]. With regard to the onset of clinical symptoms, the achievement of motor milestones, and life expectancy, SMA is divided into different subtypes (SMA types $0-4$ ). Within the 3 main types (SMA types 1-3), SMA type 1 represents the infantile onset and thus the most severe form, while SMA types 2 and 3 are defined as late-onset forms and are characterized by intermediate (SMA type 2) or mild (SMA type 3) types of progression [2]. Regardless of SMA type, typical clinical features include progressive muscle atrophy due to the degeneration of anterior horn cells, early development of joint contractures and scoliosis, and variable bulbar and respiratory weakness $[3,4]$. Scoliosis, secondary to progressive axial muscle weakness, has an incidence of $60-90 \%$ in patients with SMA types 1 and 2, starting in early childhood and invariably progressing [1, 5-7]. In adult patients, spinal deformities create mechanical disadvantages, affect posture, limit mobility and activities of daily living, and possibly increase respiratory and feeding problems [3].

Nusinersen is an antisense oligonucleotide that modifies pre-mRNA splicing to promote exon 7 inclusion in SMN2 mRNA transcripts, resulting in production of more full-length SMN protein [8, 9], which is 
clinically effective in infants with type 1 SMA and children or adults with later-onset SMA (types 2 and 3) for improving motor function $[10,11]$. This drug cannot pass the blood-brain barrier and, therefore, has to be repeatedly administered intrathecally. For most infants or young children with SMA, intrathecal delivery via a landmark-guided lumbar puncture technique has been shown to be safe, feasible and well tolerated [11]. However, in SMA patients with progressive scoliosis, standard lumbar puncture may be challenging [12-15]. Previous studies showed that computed tomography (CT)- or fluoroscopy-guided techniques could facilitate intrathecal injection of nusinersen in SMA patients with aberrant spinal anatomies [13-15]. However, potential cancer risks existing from associated ionizing radiation of computed CT or fluoroscopy scans - in particular for children, who are more radiosensitive than adults should not be ignored [16]. The real-time ultrasound-guided technique, with the advantage of avoiding radiation exposure, has been reported to be successfully used by anesthesiologists for central neuraxial block in patients with moderate to severe lumbar scoliosis $[17,18]$.

In this report, we describe our clinical experience of using the real-time ultrasound-guided technique to deliver nusinersen repeatedly in 3 SMA type 2 and 3 patients with severe scoliosis, through 15 lumbar punctures.

\section{Methods}

\section{Study participants}

The institutional review board approved this retrospective study with a waiver for informed consent. From October 30, 2019 to July 23, 2020, patients with SMA and severe scoliosis seen by the neurology physician at our institution were referred to the anesthesiology department for intrathecal nusinersen administration because of the expected difficulty in obtaining intrathecal access (Fig. 1).

\section{Pre-puncture preparation}

The purpose, methodology, and potential complications of the ultrasound-guided puncture procedure, and the benefits and side effects of nusinersen, were discussed with the patients and their parents prior to initiation of therapy and each procedure. Informed consent was obtained. Spinal 3D-CT reconstructions were obtained to ascertain intrathecal access at various lumbar levels and to facilitate pre-procedure planning (Fig. 1A-C).

\section{Ultrasound-guided lumbar puncture}

An additional movie file shows the whole process of puncture in more detail (see Additional file 1). All the punctures were performed in the operating room at the anesthesiology department. Upon arrival, standard monitoring and peripheral venous access were established for the patients. As it is important for patients to be able to communicate any concerns during the lumbar puncture procedure, sedation (intravenous midazolam) was used only when necessary to reduce the patient's severe anxiety prior to some of the 
procedures. Each patient was placed in the lateral decubitus position with the knees flexed to improve lumbar space access. The patient's head and body were supported by fitted padding. A pre-procedural ultrasound scan of the lumbar spine based on a scan protocol for scoliosis, first described by Karmakar [19], was performed using a low-frequency $(8-3 \mathrm{MHz})$, curvilinear transducer (Sonosite X-Porte; Sonosite Inc., Bothell, WA, USA). Briefly, the scan followed 3 steps. In the first step, the positions of the spinous processes (SPs) of the lumbar spine on the patient's back were palpated and marked using a skin marking pen (Fig. 1C). Next, a line connecting the SPs was drawn, referred to as the "SP line". The last step was to perform a paramedian sagittal scan by placing the transducer 1 to $2 \mathrm{~cm}$ lateral and parallel to the "SP line" with the transducer tilted slightly medially during the scan, so that the ultrasound beam was insonated in a paramedian sagittal oblique plane; this approach ensures that the ultrasound signal enters the spinal canal through the window of the interlaminar space (Figs. 2A and C). According to ultrasonography, the interlaminar spaces were visible with an acceptable acoustic window and returned good hyperechoic dura signals (Fig. 2A and Additional file 1), then the position of the transducer was marked using a skin marking pen. After sterile preparation of the posterior back with iodophor and the ultrasound transducer draped in a sterile plastic sheath, $2 \mathrm{~mL}$ of $1 \%$ lidocaine was administered as a local anesthetic. A 10-cm, 22G, echogenic needle with a short-bevel tip (SonoLong Nanoline; Pajunk Inc., Geisingen, Germany) and stylet was advanced in-plane in a caudal-to-cephalad direction (Fig. 2B) toward the interlaminar space. The needle was traced on the ultrasound screen in real time (Fig. 2C). If dural puncture was not achieved after 3 needle passes (defined as forward advancement of the needle, i.e., needle redirection without exiting the skin, including the first pass), the operator had options to change to an alternative interlaminar space level. The exact localization of the needle tip (penetrating the dura) was confirmed on ultrasound image and by free flow of clear cerebrospinal fluid (CSF) after needle stylet removal (Fig. 2C, D, and Additional file 1). After extraction of $5 \mathrm{~mL} C S F, 12 \mathrm{mg}(12 \mathrm{mg} / 5 \mathrm{~mL}$ ) of nusinersen was administrated through the needle. Subsequently, the needle was removed, and patients were placed in a comfortable position for 1 hour of observation.

\section{Data collection}

Patient characteristics including age, sex, genotype, subtype of SMA, personal history, clinical signs and symptoms, and results of CSF examination were obtained from the electronic medical records. Details of punctures (including number of interspace level adjustments and insertion attempts per procedure) were recorded. Adverse events including, but not limited to, pain or discomfort leading to need for sedation, puncture of visceral organs, post-lumbar puncture syndrome, respiratory disturbance, bleeding, and spinal ischemia were also obtained.

\section{Results}

Real-time ultrasound-guided intrathecal injections of nusinersen were performed in 3 SMA patients with severe scoliosis in the anesthesiology department at the Peking Union Medical College Hospital between October 2019 and July 2020. Clinical characteristics of the patients are described in Table 1. Two patients were diagnosed with type 3 SMA and 1 with type 2 SMA. All 3 patients completed the 4 loading 
doses and 1 maintenance dose, which accounts for a total of 15 consecutive punctures. No patients required intravenous sedation or general anesthesia. All punctures used the paramedian sagittal in-plane approach with a success rate of $100 \%$, assuring correct delivery of the drug in all patients. Among all the 15 procedures, $14(91.67 \%)$ were performed successfully at the interspace level of L4-L5, 1 at the level of L5-S1. 
Table 1

Demographics/clinical data of patients and details of lumbar punctures

\section{Clinical characteristics} Patient 1

Patient 2

Patient 3

\begin{tabular}{|c|c|c|c|}
\hline Age & 34 & 28 & 14 \\
\hline Sex & Female & Male & Female \\
\hline $\begin{array}{l}\text { Copies of SMN2 } \\
\text { gene }\end{array}$ & 3 & 3 & 3 \\
\hline SMA subtype & 3 & 2 & 3 \\
\hline Delivery mode & Natural labor & Natural labor & Natural labor \\
\hline Ambulation & Wheelchair-bound & Wheelchair-bound & $\begin{array}{l}\text { Travel short distances } \\
\text { with assistance }\end{array}$ \\
\hline Positive signs & $\begin{array}{l}\text { Symmetric severe muscle } \\
\text { weakness } \\
\text { and wasting; tongue } \\
\text { atrophy with } \\
\text { fasciculations; areflexia; } \\
\text { quadriparesis; joint } \\
\text { contractures and } \\
\text { ankylosis of the limbs }\end{array}$ & $\begin{array}{l}\text { Symmetric severe } \\
\text { muscle weakness and } \\
\text { wasting; tongue } \\
\text { atrophy with } \\
\text { fasciculations; } \\
\text { areflexia; joint } \\
\text { contractures and } \\
\text { ankylosis of the limbs }\end{array}$ & $\begin{array}{l}\text { Proximal weakness } \\
\text { affecting the legs; } \\
\text { tongue atrophy; } \\
\text { areflexia; } \\
\text { joint contractures and } \\
\text { ankylosis of both feet }\end{array}$ \\
\hline Procedures (no.) & 5 & 5 & 5 \\
\hline $\begin{array}{l}\text { Need for } \\
\text { sedation per } \\
\text { procedure ( } \mathrm{N} \text { or } \\
\mathrm{Y})\end{array}$ & $\mathrm{N} / \mathrm{N} / \mathrm{N} / \mathrm{N} / \mathrm{N}$ & $\mathrm{N} / \mathrm{N} / \mathrm{N} / \mathrm{N} / \mathrm{N}$ & $\mathrm{N} / \mathrm{N} / \mathrm{N} / \mathrm{N} / \mathrm{N}$ \\
\hline $\begin{array}{l}\text { Number of } \\
\text { interspace level } \\
\text { adjustments per } \\
\text { procedure }\end{array}$ & $2 / 2 / 1 / 1 / 1$ & $2 / 1 / 1 / 1 / 1$ & $1 / 1 / 1 / 1 / 1$ \\
\hline
\end{tabular}

Abbreviations. SMA spinal muscular atrophy, SMN survival motor neuron

a Number of total insertion attempts, defined as the number of any separate skin puncture by a needle

${ }^{b}$ Baseline neurologic function prior to first dose of nusinersen

${ }^{\mathrm{c}}$ Neurologic function after the last treatment of nusinersen

${ }^{\mathrm{d}}$ Adverse events including: headache, back pain, nausea, constipation, dizziness, upper respiratory infection 


\begin{tabular}{|c|c|c|c|}
\hline $\begin{array}{l}\text { Clinical } \\
\text { characteristics }\end{array}$ & Patient 1 & Patient 2 & Patient 3 \\
\hline $\begin{array}{l}\text { Number of total } \\
\text { insertion } \\
\text { attempts } \\
\text { procedure }\end{array}$ & $5 / 3 / 2 / 2 / 1$ & $3 / 2 / 2 / 1 / 1$ & $2 / 2 / 1 / 1 / 1$ \\
\hline $\begin{array}{l}\text { Final interspace } \\
\text { level at which } \\
\text { lumbar injection } \\
\text { was done per } \\
\text { procedure }\end{array}$ & $\begin{array}{l}\text { L5-S1/L4-L5/L4-L5/L4- } \\
\text { L5/L4-L5 }\end{array}$ & $\begin{array}{l}\text { L4-L5/L4-L5/L4-L5/L4- } \\
\text { L5/L4-L5 }\end{array}$ & $\begin{array}{l}\text { L4-L5/L4-L5/L4-L5/L4- } \\
\text { L5/L4-L5 }\end{array}$ \\
\hline $\begin{array}{l}\text { Pretreatment } \\
\text { signs and } \\
\text { symptoms }\end{array}$ & $\begin{array}{l}\text { Quadriparesis; preserved } \\
\text { hand fine motor } \\
\text { functioning to use } \\
\text { computer and write; mild } \\
\text { dysarthria; able to brush } \\
\text { her teeth }\end{array}$ & $\begin{array}{l}\text { Quadriparesis; } \\
\text { preserved hand motor } \\
\text { functioning to use } \\
\text { mouse but still has } \\
\text { difficulty in typing }\end{array}$ & $\begin{array}{l}\text { Preserved upper } \\
\text { extremity functioning to } \\
\text { feed herself, brush her } \\
\text { teeth, use mobile } \\
\text { phone, write and do } \\
\text { schoolwork }\end{array}$ \\
\hline $\begin{array}{l}\text { Posttreatment }{ }^{c} \\
\text { signs and } \\
\text { symptoms }\end{array}$ & $\begin{array}{l}\text { Louder voice; increased } \\
\text { upper limb strength; } \\
\text { improved endurance and } \\
\text { head control; able to lift } \\
\text { her left foot off the bed; } \\
\text { once able to turn over } \\
\text { autonomously }\end{array}$ & $\begin{array}{l}\text { Louder voice; improved } \\
\text { masticatory movement; } \\
\text { able to play computer } \\
\text { games; slight } \\
\text { movement of feet }\end{array}$ & $\begin{array}{l}\text { Independent kneeling } \\
\text { position and crawl } 1 \text { to } \\
2 \text { steps; able to sit up } \\
\text { on her own; caregivers } \\
\text { reported easier to } \\
\text { facilitate the patient } \\
\text { with walking }\end{array}$ \\
\hline $\begin{array}{l}\text { Hammersmith } \\
\text { Functional Motor } \\
\text { Scale-Expanded } \\
\text { score (before the } \\
\text { first/after the } \\
\text { last nusinersen } \\
\text { treatment) }\end{array}$ & $1 / 7$ & $0 / 2$ & $23 / 34$ \\
\hline Adverse events $^{d}$ & No & No & Headache and nausea \\
\hline
\end{tabular}

Abbreviations: SMA spinal muscular atrophy, SMN survival motor neuron

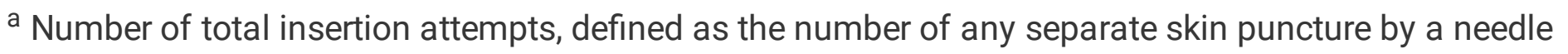

${ }^{b}$ Baseline neurologic function prior to first dose of nusinersen

${ }^{c}$ Neurologic function after the last treatment of nusinersen

${ }^{d}$ Adverse events including: headache, back pain, nausea, constipation, dizziness, upper respiratory infection

In detail, for the first puncture of Patient 1, we initially chose to inject at the level of interspace L2-L3 based on the 3D-CT image, but failed after 2 attempts because of the steep angle of the needle path, which was the only path available due to the curvature of the vertebral column. Following that, we 
changed to the level of L5-S1 based on the ultrasound image and succeeded after 2 attempts. The second puncture of Patient 1 and the first puncture of Patient 2 failed at the first attempts at level L5-S1, due to inability to withdraw CSF for uncertain reasons, even though the needle tips were seen underneath the hypoechoic dorsal dura on the ultrasound image. Finally, both punctures were successful at the second attempts at level L4-L5. For all the following procedures, level L4-L5 was selected for the first attempt and all succeeded.

All procedures were technically successful and well tolerated. Minor complications included Patient 3 reporting positional headache and nausea after the second puncture, which was resolved by bed rest. No severe complications were recorded. CSF tests and laboratory tests including platelet counts, coagulation profile, and renal and liver function tests remained unremarkable in all patients.

\section{Discussion}

In this study, we present the results of real-time ultrasound-guided lumbar intrathecal administration of nusinersen in SMA patients with severe scoliosis. The success rate was $100 \%$ with no major complications.

\section{Technique}

Lumbar puncture is a routine practice performed by anesthesiologists. The application of ultrasound in assisting lumbar puncture can be traced back to the 1970s [20], and was first used in patients with abnormal spinal anatomy in 1999 [21]. With improvements in ultrasonic imaging quality and greater understanding of the sonoanatomy of the spine among investigators, techniques of real-time ultrasoundguided spine puncture were investigated [22-25] and reported to be successfully used in patients with challenging spinal anatomy in 2010 [26]. In the current study, we chose in all procedures to use the realtime ultrasound-guided in-plane approach, advancing the needle in the plane of the ultrasound beam, through the longitudinal paramedian sagittal oblique interlaminar view, which was first described by Karmakar [23].

During lumbar spinal sonography, the paramedian sagittal oblique interlaminar approach possesses the advantage of providing a better sonographic window into the vertebral canal from the interlaminar space compared with the interspinous space (median) approach [27, 28], and is more successful in patients with a difficult anatomy $[29,30]$. Performers of the technique should be familiar with the sonoanatomy of the interlaminar, the intrathecal and the surrounding bony structures. Sonographically, the interlaminar space is the gap between the adjoining lamina and is the "acoustic window" through which the neuraxial structures are visualized within the spinal canal (Fig. 2A). The ligamentum flavum appears as a hyperechoic band across adjacent lamina (Fig. 2A). The posterior dura is the next hyperechoic structure anterior to the ligamentum flavum (Fig. 2A), and the epidural space between the ligamentum flavum and the posterior dura is hypoechoic. The ligamentum flavum and the posterior dura may also be seen as a single linear hyperechoic structure, which is referred to as the "posterior complex". The intrathecal space 
with the CSF is the anechoic space anterior to the posterior dura. The deeper linear hyperechoic structure is the "anterior complex" composed of the anterior dura, the posterior longitudinal ligament and the posterior surface of the vertebral body, which are of similar echogenicity and closely opposed to each other. To accurately obtain this paramedian sagittal oblique interlaminar window in SMA patients with complex deformity of the spine, we recommend to strictly follow the currently used 3-step scan protocol [19].

The key to the real-time ultrasound-guided in-plane technique used in this study is in obtaining and maintaining alignment of the ultrasound beam with the needle and the acoustic window into the interlaminar space during the whole procedure, which is crucial to guarantee the success of lumbar puncture [25]. Advanced skills in hand-eye coordination and needle-transducer manipulation will definitely be required to successfully perform this technique [25]. In the current study, there was no efflux of CSF in 2 punctures, though the hypoechoic "needle tips" were seen in the intrathecal space on the ultrasound image. We speculate that imprecise alignment of the needle along the ultrasound beam might have been responsible. This means that the hypoechoic dots we saw on the ultrasound image may actually represent the transverse section of the needle body, and, instead, the real needle tip had been advanced too deep into the anterior epidural space. There were another 2 failed attempts (in Patients 1 and 2) in which the intrathecal structures were clear in the ultrasound image, but we were unable to insert the needle through the interlaminar space. This may have been due to the steep needle-puncturing angle. A steeper needle-puncturing angle will inevitably attenuate the imaging quality of the needle and make it difficult to manipulate the needle based on the ultrasound image. Therefore, when determining the optimal puncture level during the pre-procedure scan, both the imaging quality of the given interlaminar space and the predicted needle-puncturing angle should be considered.

\section{Safety}

Here, we successfully and safely administered nusinersen intrathecally in all 15 procedures. No severe adverse events were noted, and only 1 patient reported positional headache and nausea after the second injection, which was resolved by bed rest. To improve the visualization of the needle under ultrasound we chose to use a $22 \mathrm{G}$ echogenic needle. The incidence of headache overall in this study was $8.3 \%$, which appears to be consistent with the post-lumbar puncture headache rate of $\sim 10 \%$ in children from previous literature [31]. In terms of safety, a prominent advantage of the current technique is its inherent radiationfree property when compared with traditionally used fluoroscopy- or CT-guided technique. As therapy with nusinersen is long term, the cumulative radiation exposure from repeated puncture may be of concern, because of its deleterious effects for human health in inducing cancers (e.g. colon cancer, lung cancer and leukemia) $[13,16]$. Additionally, by using the real-time ultrasound-guided technique, advancement of the needle could be visualized during the whole procedure, which is particularly helpful in avoiding unnecessary vascular or visceral injuries.

\section{Limitations}


The current study has several limitations. First, this is a retrospective evaluation of a method that has been used in only a few patients. However, the objective of this study was to evaluate the feasibility of performing real-time ultrasound guidance for SMA patients with severe scoliosis, which we have successfully demonstrated. Second, our experience is mainly based on patients with severe scoliosis but not previous spinal surgery. Spinal surgery for rod placement or fusion is a common treatment for SMA patients to control their progressive scoliosis [32], which may present greater challenges for lumbar puncture since the interlaminar approach may not be feasible in these complex conditions. Ultrasound has seldom been used in this population of patients, except for one report describing ultrasound-guided cervical puncture for difficult lumbar nusinersen delivery in SMA patients with previous spinal instrumentation [33]. However,successful use of ultrasound assistance or real-time guidance to facilitate a difficult interlaminar lumbar puncture for other purposes in patients with spinal fusion instrumentation $[21,26,34]$ has been reported previously. Similarly, the transforaminal lumbar injection technique, which has been used under CT guidance for intrathecal access in patients with spinal fusion where a interlaminar approach is often not possible, has also been reported to be successfully performed with ultrasound guidance in other circumstances $[35,36]$. Therefore, the value of ultrasound guidance in SMA patients with spinal fusion is worthy of attention and exploration.

\section{Conclusion}

The real-time ultrasound-guided technique can be successfully used to assist lumbar nusinersen administration in SMA patients with severe scoliosis. The advantage of the current technique is that it is free of exposure to radiation, provides real-time images, and improves patient comfort during the whole procedure. A sound knowledge of the sonoanatomy of the spinal deformity and skilled manipulation techniques are needed for practitioners to apply this technique safely and effectively.

\section{Declarations}

\section{Ethics approval and consent to participate}

This study protocol was approved by the Institutional Review Boards of the Peking Union Medical College Hospital (No. S-K 1378). And all the subjects or their legal representatives gave written informed consent.

\section{Consent for publication}

Consent for publication was obtained from all involved persons (or from their legal representatives), whose images were used in the present manuscript.

\section{Availability of data and materials}

All study data, including raw and analyzed data, and materials will be available from the corresponding author on reasonable request. 


\section{Competing interests}

The authors declare that they have no competing interests.

\section{Funding}

The study was supported by the Center for Rare Diseases Research, Chinese Academy of Medical Sciences, Beijing, China and the National Key Research and Development Program of China Grant No. 2016YFC0901500.

\section{Authors' contributions}

JZ facilitated lumbar punctures, performed statistical analysis and was a major contributor in writing the manuscript. XC designed the study, performed lumbar punctures, and revised the manuscript. SC facilitated lumbar punctures and revised the manuscript. YD revised the manuscript, and supervised lumbar punctures. YH revised the manuscript. SZ designed the study and revised the manuscript. All authors critically revised and approved the final manuscript.

\section{Acknowledgments}

The authors thank the patients who participated in this study and their parents. The authors also thank $\mathrm{Dr}$ Yuelun Zhang for providing advice and assistance in data analysis, and the nurses in the operating room of the Peking Union Medical College Hospital who contributed to the study.

\section{References}

1. Crawford TO, Pardo CA. The neurobiology of childhood spinal muscular atrophy. Neurobiol Dis. 1996;3(2):97-110.

2. Lunn MR, Wang CH. Spinal muscular atrophy. Lancet. 2008;371(9630):2120-33.

3. Wang CH, Finkel RS, Bertini ES, Schroth M, Simonds A, Wong B, et al. Consensus statement for standard of care in spinal muscular atrophy. J Child Neurol. 2007;22(8):1027-49.

4. D'Amico A, Mercuri E, Tiziano FD, Bertini E. Spinal muscular atrophy. Orphanet J Rare Dis. 2011;6:71.

5. Schwentker EP, Gibson DA. The orthopaedic aspects of spinal muscular atrophy. J Bone Joint Surg Am. 1976;58(1):32-38.

6. Mercuri E, Bertini E, lannaccone ST. Childhood spinal muscular atrophy: controversies and challenges. Lancet Neurol. 2012;11(5):443-52.

7. Fujak A, Raab W, Schuh A, Richter S, Forst R, Forst J. Natural course of scoliosis in proximal spinal muscular atrophy type II and IIla: descriptive clinical study with retrospective data collection of 126 patients. BMC Musculoskelet Disord. 2013;14:283.

8. Passini MA, Bu J, Richards AM, Kinnecom C, Sardi SP, Stanek LM, et al. Antisense oligonucleotides delivered to the mouse CNS ameliorate symptoms of severe spinal muscular atrophy. Sci Transl 
Med. $2011 ; 3(72): 18 r-72 r$.

9. Finkel RS, Mercuri E, Darras BT, Connolly AM, Kuntz NL, Kirschner J, et al. Nusinersen versus sham control in infantile-onset spinal muscular atrophy. N Engl J Med. 2017;377(18):1723-32.

10. Mercuri E, Darras BT, Chiriboga CA, Day JW, Campbell C, Connolly AM, et al. Nusinersen versus sham control in later-onset spinal muscular atrophy. N Engl J Med. 2018;378(7):625-35.

11. Hache M, Swoboda KJ, Sethna N, Farrow-Gillespie A, Khandji A, Xia S, et al. Intrathecal injections in children with spinal muscular atrophy: nusinersen clinical trial experience. J Child Neurol. 2016;31(7):899-906.

12. Bortolani S, Stura G, Ventilii G, Vercelli L, Rolle E, Ricci F, et al. Intrathecal administration of nusinersen in adult and adolescent patients with spinal muscular atrophy and scoliosis: transforaminal versus conventional approach. Neuromuscul Disord. 2019;29(10):742-6.

13. Weaver JJ, Natarajan N, Shaw D, Apkon SD, Koo KSH, Shivaramet GM, et al. Transforaminal intrathecal delivery of nusinersen using cone-beam computed tomography for children with spinal muscular atrophy and extensive surgical instrumentation: early results of technical success and safety. Pediatr Radiol. 2018;48(3):392-7.

14. Geraci AP, Black K, Jin M, Rimler S, Evans A. Transforaminal lumbar puncture for intrathecal nusinersen administration. Muscle Nerve. 2018 Jan 24. doi: 10.1002/mus.26082.

15. Nascene DR, Ozutemiz C, Estby H, McKinney AM, Rykken JB. Transforaminal lumbar puncture: an alternative technique in patients with challenging access. AJNR Am J Neuroradiol. 2018;39(5):98691.

16. Pearce MS, Salotti JA, Little MP, McHugh K, Lee C, Kim KP, et al. Radiation exposure from CT scans in childhood and subsequent risk of leukaemia and brain tumours: a retrospective cohort study. Lancet. 2012;380(9840):499-505.

17. Elsharkawy H, Maheshwari A, Babazade R, Perlas A, Zaky S, Mounir-Soliman L. Real-time ultrasoundguided spinal anesthesia in patients with predicted difficult anatomy. Minerva Anestesiol. 2017;83(5):465-73.

18. Chin KJ, Perlas A, Chan V, Brown-Shreves D, Koshkin A, Vaishnav V. Ultrasound imaging facilitates spinal anesthesia in adults with difficult surface anatomic landmarks. Anaesthesiology. 2011;115(1):94-101.

19. Karmakar MK. Musculoskeletal ultrasound for regional anaesthesia and pain medicine. 2 nd ed. Hong Kong: The Chinese University of Hong Kong, 2016.

20. Bogin IN, Stulin ID. Application of the method of 2-dimensional echospondylography for determining landmarks in lumbar punctures [Article in Russian]. Zh Nevropatol Psikhiatr Im S S Korsakova. 1971;71(12):1810-11.

21. Yeo ST, French R. Combined spinal-epidural in the obstetric patient with Harrington rods assisted by ultrasonography. Br J Anaesth. 1999;83(4):670-2.

22. Grau T, Leipold RW, Fatehi S, Martin E, Motsch J. Real-time ultrasonic observation of combined spinal-epidural anaesthesia. Eur J Anaesthesiol. 2004;21(1):25-31. 
23. Karmakar MK, Li X, Ho AM, Kwok WH, Chui PT. Real-time ultrasound-guided paramedian epidural access: evaluation of a novel in-plane technique. Br J Anaesth. 2009;102(6):845-54.

24. Tran D, Kamani AA, Al-Attas E, Lessoway VA, Massey S, Rohling RN. Single-operator real-time ultrasound-guidance to aim and insert a lumbar epidural needle. Can J Anaesth. 2010;57(4):313-21.

25. Karmakar MK, Li X, Kwok WH, Ho AM, Ngan KW. Sonoanatomy relevant for ultrasound-guided central neuraxial blocks via the paramedian approach in the lumbar region. $\mathrm{Br} \mathrm{J}$ Radiol. 2012;85(1015):e262-9.

26. Chin KJ, Chan VW, Ramlogan R, Perlas A. Real-time ultrasound-guided spinal anesthesia in patients with a challenging spinal anatomy: two case reports. Acta Anaesthesiol Scand. 2010;54(2):252-5.

27. Chin KJ, Perlas A, Singh M, Arzola C, Prasad A, Chan V, et al. An ultrasound-assisted approach facilitates spinal anesthesia for total joint arthroplasty. Can J Anaesth. 2009;56(9):643-50.

28. Grau T, Leipold RW, Horter J, Conradi R, Martin EO, Motsch J. Paramedian access to the epidural space: the optimum window for ultrasound imaging. J Clin Anesth. 2001;13(3):213-7.

29. Podder S, Kumar N, Yaddanapudi LN, Chari P. Paramedian lumbar epidural catheter insertion with patients in the sitting position is equally successful in the flexed and unflexed spine. Anesth Analg. 2004;99(6):1829-32.

30. Rabinowitz A, Bourdet B, Minville V, Chassery C, Pianezza A, Colombani A, et al. The paramedian technique: a superior initial approach to continuous spinal anesthesia in the elderly. Anesth Analg. 2007;105(6):1855-7.

31. Lee LC, Sennett M, Erickson JM. Prevention and management of post-lumbar puncture headache in pediatric oncology patients. J Pediatr Oncol Nurs. 2007;24(4):200-7.

32. McElroy MJ, Shaner AC, Crawford TO, Thompson GH, Kadakia RV, Akbarnia BA, et al. Growing rods for scoliosis in spinal muscular atrophy: structural effects, complications, and hospital stays. Spine (Phila Pa 1976). 2011;36(16):1305-11.

33. Ortiz CB, Kukreja KU, Lotze TE, Chau A. Ultrasound-guided cervical puncture for nusinersen administration in adolescents. Pediatr Radiol. 2019;49(1):136-40.

34. Costello JF, Balki M. Cesarean delivery under ultrasound-guided spinal anesthesia [corrected] in a parturient with poliomyelitis and Harrington instrumentation. Can J Anaesth. 2008;55(9):606-11.

35. Gofeld M, Bristow SJ, Chiu SC, McQueen CK, Bollag L. Ultrasound-guided lumbar transforaminal injections: feasibility and validation study. Spine (Phila Pa 1976). 2012;37(9):808-12.

36. Zhang MB, Yan LT, Li SP, Li YY, Huang P. Ultrasound guidance for transforaminal percutaneous endoscopic lumbar discectomy may prevent radiation exposure: a case report. World J Clin Cases. 2019;7(10):1161-8.

\section{Figures}



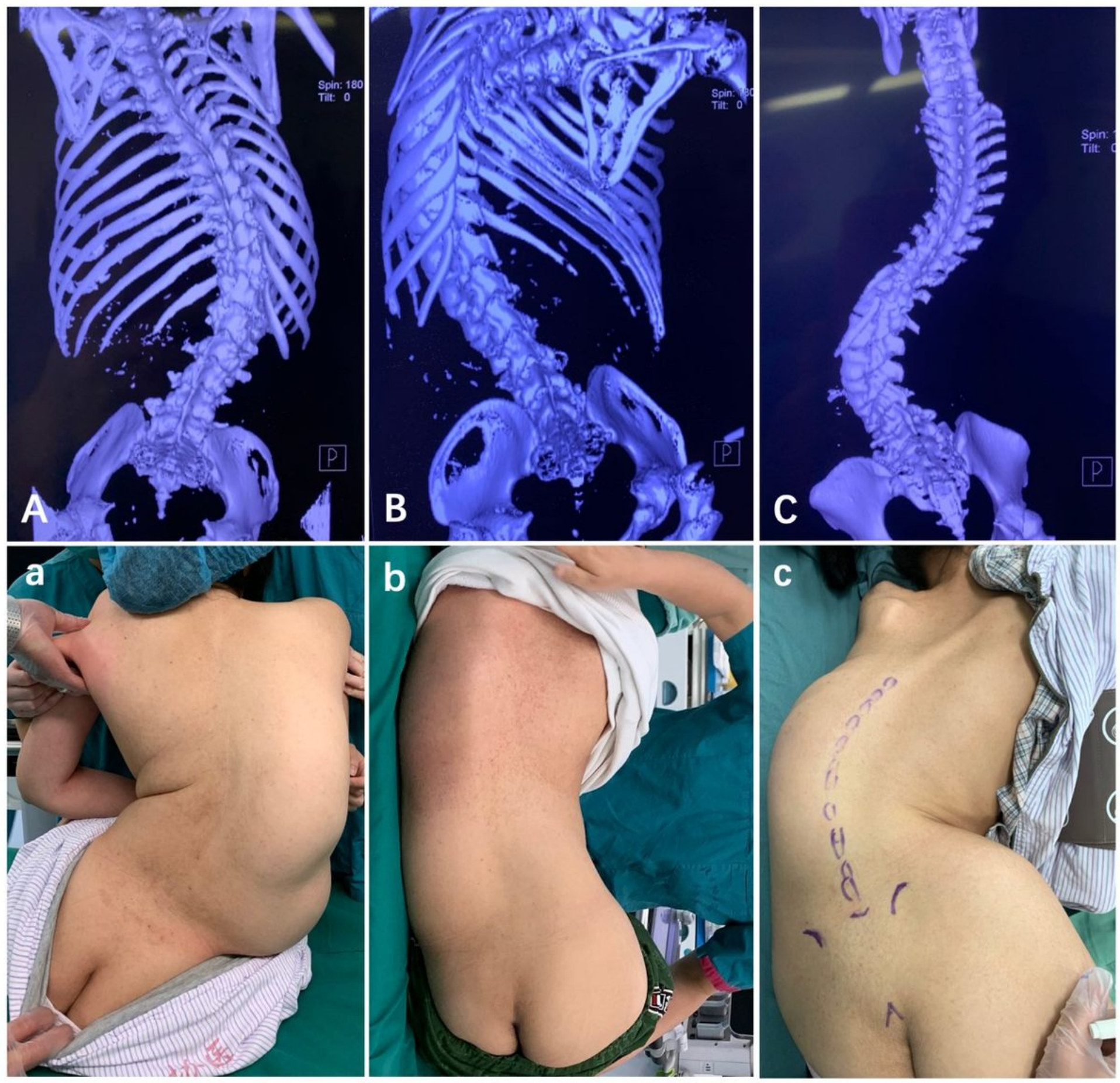

\section{Figure 1}

Three-dimensional CT images and appearance of the back in the 3 SMA patients with severe scoliosis. (A) and (a) from Patient 1, (B) and (b) from Patient 2, (C) and (c) from Patient 3 


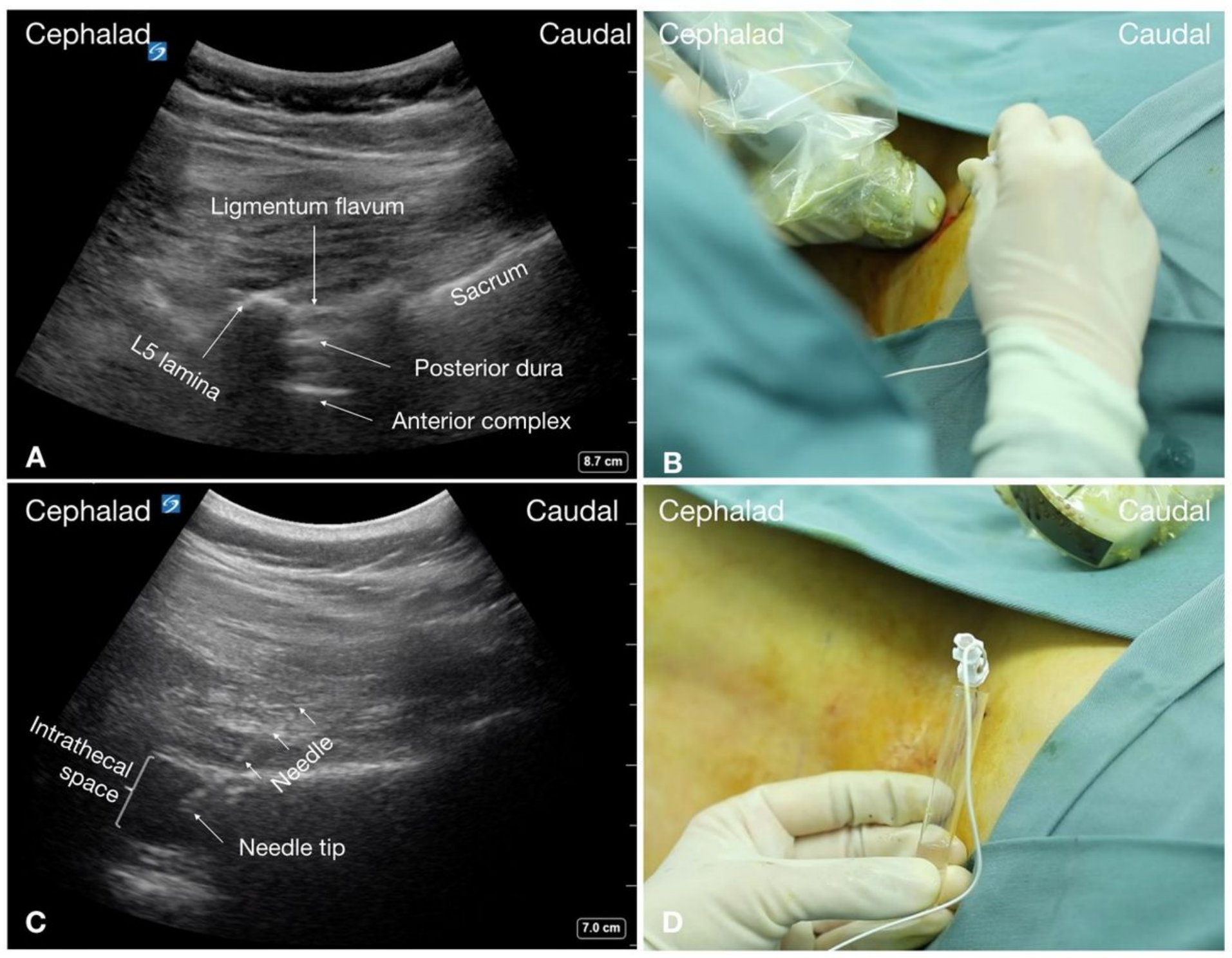

Figure 2

Real-time ultrasound-guided lumbar puncture in SMA patient with severe scoliosis. (A) Paramedian sagittal oblique interlaminar sonogram of the lower lumbar spine (L5-S1) with the neuraxial structures clearly visualized through the acoustic window of the interlaminar space. (B) Ultrasound probe position of paramedian sagittal oblique scan at the level of lamina and needle orientation for lumbar puncture with in-plane approach. (C) Sonogram obtained when needle inserted into the intrathecal space. (D) Free flow of clear CSF is noted from the puncture needle

\section{Supplementary Files}

This is a list of supplementary files associated with this preprint. Click to download.

- OperationVideo.mp4

- STROBEchecklist.pdf 